\title{
Predicting breast cancer response to neoadjuvant chemotherapy using pretreatment diffuse optical spectroscopic texture analysis
}

William T Tran ${ }^{1,2}$, Mehrdad J Gangeh ${ }^{1}$, Lakshmanan Sannachi ${ }^{1,3}$, Lee Chin ${ }^{1}$, Elyse Watkins ${ }^{1}$, Silvio G Bruni ${ }^{4}$, Rashin Fallah Rastegar ${ }^{4}$, Belinda Curpen ${ }^{4}$, Maureen Trudeau ${ }^{5}$, Sonal Gandhi ${ }^{5}$, Martin Yaffe ${ }^{6}$, Elzbieta Slodkowska ${ }^{7}$, Charmaine Childs ${ }^{2}$, Ali Sadeghi-Naini ${ }^{1,3,6,8}$ and Gregory J Czarnota*,1,3,6,8

${ }^{1}$ Department of Radiation Oncology, Sunnybrook Health Sciences Centre, 2075 Bayview Avenue, Toronto, Ontario M4N 3M5, Canada; ${ }^{2}$ Centre for Health and Social Care Research, Sheffield Hallam University, 32 Collegiate Crescent, Sheffield S10 2BP, UK; ${ }^{3}$ Department of Medical Biophysics, University of Toronto, 2075 Bayview Avenue, Toronto, Ontario M4N 3M5, Canada; ${ }^{4}$ Department of Medical Imaging, Sunnybrook Hospital, 2075 Bayview Avenue, Toronto, Ontario M4N 3M5, Canada; ${ }^{5}$ Division of Medical Oncology, Department of Medicine, Sunnybrook Health Sciences Centre, 2075 Bayview Avenue, Toronto, ON M4N 3M5, Canada; ${ }^{6}$ Physical Sciences Platform, Sunnybrook Research Institute, 2075 Bayview Avenue, Toronto, Ontario M4N 3M5, Canada; ${ }^{7}$ Department of Anatomic Pathology, Sunnybrook Health Sciences Centre, 2075 Bayview Avenue, Toronto, Ontario M4N 3M5, Canada and ${ }^{8}$ Department of Radiation Oncology, University of Toronto, 2075 Bayview Avenue, Toronto, Ontario M4N 3M5, Canada

Background: Diffuse optical spectroscopy (DOS) has been demonstrated capable of monitoring response to neoadjuvant chemotherapy (NAC) in locally advanced breast cancer ( $L A B C)$ patients. In this study, we evaluate texture features of pretreatment DOS functional maps for predicting $L A B C$ response to NAC.

Methods: Locally advanced breast cancer patients $(n=37)$ underwent DOS breast imaging before starting NAC. Breast tissue parametric maps were constructed and texture analyses were performed based on grey-level co-occurrence matrices for feature extraction. Ground truth labels as responders (R) or non-responders (NR) were assigned to patients based on Miller-Payne pathological response criteria. The capability of DOS textural features computed on volumetric tumour data before the start of treatment (i.e., 'pretreatment') to predict patient responses to NAC was evaluated using a leave-one-out validation scheme at subject level. Data were analysed using a logistic regression, naive Bayes, and k-nearest neighbour classifiers.

Results: Data indicated that textural characteristics of pretreatment DOS parametric maps can differentiate between treatment response outcomes. The $\mathrm{HbO}_{2}$ homogeneity resulted in the highest accuracy among univariate parameters in predicting response to chemotherapy: sensitivity (\%Sn) and specificity (\%Sp) were $86.5 \%$ and $89.0 \%$, respectively, and accuracy was $87.8 \%$. The highest predictors using multivariate (binary) combination features were the $\mathrm{Hb}$-contrast $+\mathrm{HbO}_{2}$-homogeneity, which resulted in a \% Sn/ $\% \mathrm{Sp}=78.0 / 81.0 \%$ and an accuracy of $79.5 \%$.

Conclusions: This study demonstrated that the pretreatment DOS texture features can predict breast cancer response to NAC and potentially guide treatments.

*Correspondence: Dr GJ Czarnota; E-mail: gregory.czarnota@sunnybrook.ca

Received 7 March 2017; revised 16 March 2017; accepted 17 March 2017; published online 18 April 2017

(C) 2017 Cancer Research UK. All rights reserved 0007-0920/17 
Breast cancer is the second leading cause of cancer-related mortality in women, and accounts for approximately one-third of new malignancies (Desantis et al, 2014). Nearly 20\% of cases present as locally advanced breast cancer (LABC), which are characterised as stage IIB or stage III disease; thus, having large/ bulky tumours which are often $>5 \mathrm{~cm}$ in size and involving the lymph nodes or skin (Giordano, 2003; Whitman and Strom, 2009). Survival outcomes for LABC are poor; only $50 \%$ of patients survive beyond 5 years (Lee and Newman, 2007). Guidelines from the National Institute for Health and Care Excellence (NICE) in the United Kingdom recommend neoadjuvant chemotherapy (NAC) for clinical management to downstage tumours prior to locoregional treatment with surgery and radiotherapy (Cance et al, 2002; Lee and Newman, 2007; National Institute For Health And Clinical Excellence (NICE), 2009). However, variable tumour responses have been shown in patients receiving NAC and there is evidence to suggest that favourable response to NAC correlates to improved disease-free survival (DFS) (Mathew et al, 2009; von Minckwitz et al, 2012).

Measuring tumour response at early stages of NAC may help guide treatments for potentially improved DFS. Standard methods use clinical palpation or medical imaging such as magnetic resonance imaging (MRI) to measure anatomical changes (Eisenhauer et al, 2009). However major limitations include variability in reader expertise, image reproducibility, and the time delay between biological and anatomical changes (Eisenhauer et al, 2009; Roblyer et al, 2011). Thus, emerging studies are investigating quantitative imaging methods to evaluate tumour response based on functional and biological tumour alterations to NAC within days to weeks after treatment initiation (Jakubowski et al, 2004; Roblyer et al, 2011). Recent studies have indicated that diffuse optical spectroscopy (DOS) imaging can characterise tumour response by focusing on changes in tissue composition (Cerussi et al, 2007; Roblyer et al, 2011; Jiang et al, 2014). Maps of tumour physiological features, such as haemoglobin are computed from tissue optical properties that are based on near-infrared optical scattering and absorption (Cerussi et al, 2006). For breast tissue, significant optical absorbers include oxy-haemoglobin $\left(\mathrm{HbO}_{2}\right)$, deoxy-haemoglobin $(\mathrm{Hb})$, water $\left(\mathrm{H}_{2} \mathrm{O}\right)$, and lipids ( $\mathrm{Li}$ ) (Cerussi et al, 2006). Their concentrations can be estimated by measuring the absorption coefficient $\left(\mu_{\mathrm{a}}\right)$ and using Beer's law equation (Cerussi et al, 2011). Also, tissue optical parameters such as the reduced scattering coefficient $\left(\mu_{s}^{\prime}\right)$ can provide additional information on tissue microstructure $(\sim 0.2 \mu \mathrm{m})$, corresponding to optical scattering effects from mitochondria and the cell nucleus (Mourant et al, 2000; Cerussi et al, 2006). In previous studies, changes in DOS markers such as $\mathrm{HbO}_{2}$ have been correlated to tumour response within 1 week of starting NAC (Roblyer et al, 2011) and after several cycles of chemotherapy (Schaafsma et al, 2015). A study by Ueda et al (2012) also measured baseline tumour oxygen saturation $\left(\mathrm{StO}_{2}\right)$ prior to NAC and reported significantly higher $\mathrm{StO}_{2}$ in tumours that demonstrated pathological complete response (pCR) vs non-pCR.

Second-order statistical analysis of DOS parametric images can also yield texture features and aid in discriminating tumour response during NAC (Sadeghi-Naini et al, 2015). Feature extraction methods such as those based on grey-level cooccurrence matrices (GLCM) can be applied to compute the probabilities of relative pixel intensities of images from the spatial distribution of their voxels (Haralick et al, 1973). Grey-level cooccurrence matrices texture features include contrast (con), correlation (cor), homogeneity (hom), and energy (ene), and are dependent on the number of grey-levels $\left(N_{g}\right)$ in the image or within the region of interest (ROI). Such techniques have been applied to several modalities, such as X-ray mammography ( $\mathrm{Li}$ et al, 2005), MRI (Lerski et al, 1993; Chen et al, 2007), positronemission tomography (Chicklore et al, 2013), and ultrasound
(Yang et al, 2012) in order to discriminate and characterise tissue types (Castellano et al, 2004). In breast studies, GLCM analysis has been able to classify benign and malignant lesions using planar (2D) and volumetric (3D) MRI images (Gibbs and Turnbull, 2003; Chen et al, 2007). For X-ray mammography, GLCM analysis has been used to segment lesion borders of stellate (malignant) breast masses (Gupta and Undrill, 1995). It was also recently reported that texture-based features from quantitative ultrasound imaging can be used to classify responders and non-responders early during NAC treatment (Sadeghi-Naini et al, 2014). These previous findings suggested that textural features may detect the acute, heterogeneous microstructural features carried in the parametric layout (Sadeghi-Naini et al, 2014). The research here is built on those previous findings but focusses on the pretreatment DOS texture features of the tumour area in 37 patients with LABC.

The aims of the present study were to carry out baseline DOS texture analysis to characterise pretreatment tumour heterogeneity as a marker for NAC response. Diffuse optical spectroscopy breast maps were acquired in LABC before treatment and here, texture features were used to predict treatment response (responder $v s$ non-responder) based on three classifier models: a logistic regression analysis, naive Bayes, and $k$-nearest neighbour $(k-\mathrm{NN}))$. The classification ground truth was based on final Miller-Payne (MP) pathologic response criteria. The results of this study demonstrate a significant difference $(P<0.05)$ in the DOS textural features between response groups for features such as the $\mathrm{Hb}$-hom and $\mathrm{StO}_{2}$-con. The results indicate that textural characteristics of pretreatment DOS parametric maps can serve as predictors of pathological response to NAC. Diffuse optical spectroscopy imaging biomarkers could potentially help guide treatment for improved treatment outcomes in LABC patients, and for tailoring personalised treatment.

\section{MATERIALS AND METHODS}

Patient treatment and response criteria. This study was approved by the institutional research ethics board at Sunnybrook Health Sciences Centre, Toronto, Canada and all patients signed a written informed consent before participating in the study. Patients $(n=37)$ were included following a biopsy-confirmed diagnosis of LABC, aged 18-85, and were recommended for NAC. As part of the patient's standard of care, tumour molecular and histological features such as: oestrogen receptor (ER) status, progesterone receptor (PR) status, and human epidermal growth factor receptor amplification (Her2/Neu) were determined during the patient's diagnostic work-up. Patients had pretreatment MRI for initial size measurements. Clinical data were recorded in the patient's electronic medical record and retrieved for this study.

Neoadjuvant chemotherapy consisted of combination anthracycline- and taxane-based therapy for 6-8 cycles. These included combination therapies of either AC-T (Adriamycin, Cyclophosphamide, Taxol) or FEC-D (Fluorouracil, Epirubicin, Cyclophosphamide, Docetaxel). For Her2/Neu-amplified tumours, patients also received Trastuzumab concurrently with taxanes. Patients were clinically assessed by physical examination for the duration of treatment by their medical oncologist. Patients were assessed for NAC response pathologically using MP criteria (Ogston et al, 2003; Provenzano et al, 2015). MP criteria is a five-point grading system where MP-5 indicates no malignant cells identified in the tumour bed after treatment; MP-4 indicates a significant disappearance of tumour cells ( $>90 \%$ loss of tumour cells); MP-3 indicates a 30-90\% disappearance of tumour cells; and MP-2 and MP-1 indicate no change or minor loss $(<30 \%)$ of tumour cells (Ogston et al, 2003). Patients were considered responders (R) if there was at least a $30 \%$ reduction in tumour cells under microscopy (i.e., MP 
3-5) (Ogston et al, 2003). Patients were otherwise classified as nonresponders (NR) (MP 1-2). On the basis of these criteria, 27 patients were classified as responders and 10 patients were nonresponders; that is, the ratio of responders to non-responders was $\sim 3$. This labelling was used as the ground truth in the classifiers analyses performed as explained in the next subsections.

Tomographic diffuse optical spectroscopy imaging. Timedomain DOS imaging was performed on the patient's breast prior to the start of NAC, using a commercially developed tomographic DOS imaging device (SoftScan, Montreal, QC, Canada). Patients were laid prone with the breast positioned inside an imaging chamber. The breast was stabilised with compression plates in the craniocaudal direction and optical compensation medium was added for optical coupling between surfaces $\left(\mu_{\mathrm{a}}=0.04 \mathrm{~cm}^{-1}\right.$; $\mu_{\mathrm{s}}=11 \mathrm{~cm}^{-1}$ (Intes, 2005)). Near-infrared light transmission was carried out using four individually pulsed semiconductor diode lasers operating at $690,730,780$, and $830 \mathrm{~nm}$, with a pulse duration of $<150 \mathrm{ps}, 20 \mathrm{MHz}$ repetition frequency, and an average power of $0.5 \mathrm{~mW}$ (PicoQuant, Berlin, Germany). Optical detection used five output-fibered collimators that collected photons transmitted through the breast. Fibered collimators were coupled to photomultiplier tubes (Hamamatsu, Bridgewater, NJ, USA) and directed to a photon counting module (Becker \& Hickl, Berlin, Germany). The temporal-point spread function was measured and used to compute the absorption $\left(\mu_{\mathrm{a}}\right)$ and scattering $\left(\mu_{\mathrm{s}}\right)$ coefficients based on photon diffusion theory in tissue (Xu and Povoski, 2007).

Parametric data included measurements of dominant DOS chromophores in breast comprising of $\mathrm{HbO}_{2}$ and $\mathrm{Hb}$ (Cerussi et al, 2006). The absorbance spectra of these tissue components were used to determine their concentrations $(C)$ using the Beer-Lambert law, with known molar extinction coefficients $(\varepsilon)$ (Equation 1):

$$
\mu_{\mathrm{a}}=\varepsilon \times C
$$

Other DOS parameters, such as \%water, \%lipid, scattering power $(b)$, and scattering amplitude $(A)$ were measured using the powerlaw fit of the scattering spectra within a given wavelength $(\lambda)$ (Equation 2). This relationship is based on a Mie scattering approximation (Tromberg et al, 2005):

$$
\mu_{\mathrm{s}}(\lambda)=A \times \lambda^{b}
$$

Additionally, other optical parameters such as $\mathrm{StO}_{2}$, oxygen desaturation (St), total haemoglobin ( $\mathrm{HbT})$, and the tissue optical index (TOI) were calculated from the $\mathrm{Hb}, \mathrm{HbO}_{2}, \%$ water, and $\%$ lipid, and these calculations have been described elsewhere (Intes, 2005; Cerussi et al, 2011).

DOS texture analysis. Whole-breast tomographic DOS parametric maps were constructed with an in-plane resolution of $3 \times 3 \mathrm{~mm}^{2}$ and slice thickness of $7.5 \mathrm{~mm}$. The ROI was an ellipsoid contour that was manually annotated around the tumour (Review Workstation, SoftScan; Schaafsma et al, 2015). Tumour ROIs were also selected with reference to the patients' pretreatment MRI with breast radiologists (BC, SGB, RFR).

Grey-level co-occurrence matrices texture analysis was performed on tomographic DOS data for the entire tumour volume and averaged over multiple frames; corresponding to the DOS parameters. A bilinear interpolation was applied to compensate for differences in the spatial resolutions, thus obtaining volumetric images with isotropic voxels $\left(3 \times 3 \times 3 \mathrm{~mm}^{3}\right.$; Sadeghi-Naini et al, 2015). For the GLCM, grey-tone intensities $\left(N_{g}\right)$ were quantised into 16 grey-levels from the DOS parametric maps. A symmetric GLCM was constructed based on the spatial relationship of each voxel's neighbours using a displacement vector; the magnitude of the displacement vector was one to four voxel distances. A cumulative GLCM was calculated in 13 directions ( $45^{\circ}$ rotations in each adjacent direction) relative to the central voxel (Chen et al, 2007). The resulting co-occurrence features included: energy, homogeneity, contrast, and correlation. These were previously defined by (Haralick et al (1973)):

$$
\text { Energy (Ene) }=\sum_{i=1}^{N_{g}} \sum_{j=1}^{N_{g}} g_{i j}^{2}
$$

where the energy (angular second moment) describes the textural uniformity of the image, $0 \leqslant$ Ene $\leqslant 1$, and $g_{i j}$ is the $i$ th and $j$ th entry of the GLCM representing a grey-tone intensity in the matrix;

$$
\text { Homogeneity (Hom) }=\sum_{i=1}^{N_{g}} \sum_{j=1}^{N_{g}} \frac{1}{1+(i-j)^{2}} g_{i j}
$$

where the homogeneity (inverse difference moment) measures the diagonal elements within the displacement vector of the GLCM and relates the similarities in grey tones between voxels;

$$
\text { Contrast (Con) }=\sum_{i=1}^{N_{g}} \sum_{j=1}^{N_{g}}(i-j)^{2} g_{i j}
$$

where the contrast measures the differences between the lowest and highest voxels' grey tones and finally;

$$
\text { Correlation }(\text { Cor })=\frac{\sum_{i=1}^{N_{g}} \sum_{j=1}^{N_{g}}(i j) g-\mu_{x} \mu_{y}}{\sigma_{x} \sigma_{y}}
$$

where the correlation measures the linear dependency on neighbouring grey-tone intensities; and $\sigma_{x}, \sigma_{y}$ are the s.d., and $\mu_{x}, \mu_{y}$ are the means of the probability matrix. Therefore, a total of 40 DOS texture features was included for analysis; there were 10 DOS parameters comprised of four GLCM features for each parameter (Supplementary Figure 1). Diffuse optical spectroscopy texture features were calculated using MatLab R2011b (The MathWorks Inc., Natick, MA, USA).

Statistical analysis and classification. All statistical analyses were performed using SPSS V.22 (IBM Corp., Armonk, NY, USA) and MatLab R2011b (The MathWorks Inc.). The DOS-GLCM features were compared for significant differences between $\mathrm{R}$ and NR patients $(n=37)$. Additionally, a subgroup analysis was completed based on tumour molecular features and chemotherapy treatments. The subgroups included ER $+(n=27)$, 'triple-negative' (ER $-/$ $\mathrm{PR}-/ \mathrm{HER} 2-; n=7)$, FEC-D $(n=16)$ and AC-T $(n=21)$ chemotherapy. HER2 + patients were not considered due to the limited number of non-responders in this subgroup $(n=2)$. For the classifiers to be used, at least three subjects are needed within each response group to perform the leave-one-subject-out validation scheme; as it may happen that one subject be in the test set, one in the validation set, and therefore, one additional subject is needed in the training set.

Comparisons were first tested for normality violations using a Shapiro-Wilk test. Normally distributed parameters were tested for significance using an unpaired $t$-test (two-sided within the 95\% confidence interval). Otherwise, a Mann-Whitney test was performed (two-sided, 95\% confidence).

In this study, a logistic regression analysis, a naive Bayes classification method, and a $k$-NN classifier were used to analyse the predictive value of DOS-GLCM features. A naive Bayes classification method assumes that features are independent of each other within the class variable. The $k$-NN classifier considers a test point and analyses the neighbouring points to form a class based on the frequency and distance between points. Four performance measures including the sensitivity (\%Sn), specificity $(\% \mathrm{Sp})$, accuracy, and area under curve (AUC) of the receiveroperating characteristic (ROC) were calculated for both univariate parameters and multivariate parameters. These measures were used to compare the performance of the three classifiers. Prior to training and test validation, the data set was randomly subsampled 
into 20 subsets with replacement. Each subset had equal numbers of responders and non-responders; this method was used to account for the data imbalance between the two response groups. Since each patient was represented using 40 DOS-GLCM features, and due to a limited sample size, in order to prevent the 'curse of dimensionality' (Jain et al, 2000), a feature selection based on sequential forward selection (SFS) algorithm in a wrapper framework (Duda et al, 2001) was performed to find the best (in the univariate case) or at most two (in the multivariate case) features. In order to prevent the peaking phenomenon due to the curse of dimensionality (Jain et al, 2000), the number of features should be at most 1/10th of the number of data samples, and since in the balanced data, there were only 20 data samples, a maximum of two features were selected for multivariate analysis using the SFS algorithm. The classifiers were evaluated using a leave-one-out cross validation at subject level. At each fold, the test set (one patient) remained unseen during the feature selection, tuning, and training of a classifier. Furthermore, at each fold, a leaveone-out cross validation was performed on the training set for the purpose of feature selection and tuning a classifier parameter (such as $k$ in $k$-NN). Thus, at each fold, the training set was further divided into training and validation sets. The most discriminative feature(s) and the optimal classifier parameter were selected on the training set at each fold without involving the left-out test sample. Subsequently at each fold, the classifier was trained on the whole-training set using the optimal classifier parameter and selected features, and tested on the test sample. This process was repeated on all samples (in the leave-one-out process) to evaluate the performance of the classifier.

In order to test if there was a correlation between DOS-GLCM features and tumour biology and clinical features, a multiple linear regression analysis was completed using methods previously reported for imaging biomarker analysis (Evans et al, 2013). The following clinical variables were considered in the model: Patient's age, ER/PR status, Her2 status, tumour size, and pathologic response. The regression coefficient $(r)$ was calculated between the clinical variables and DOS-GLCM features. A statistical test of significance was also performed using an ANOVA test with an alpha of 0.05.

\section{RESULTS}

Patient characteristics. This study included $n=37$ patients with biopsy-confirmed LABC. The median age of subjects was 50 years old. The mean tumour size in the largest dimension prior to NAC was $5.4 \mathrm{~cm}$ for responders and $7.0 \mathrm{~cm}$ for non-responders. The molecular features of tumours indicated that 27 patients were ER/ PR positive. A total of 12 patients were Her2/Neu positive. A total of $n_{1}=27$ patients were classified as responders and $n_{2}=10$ patients as non-responders based on the ultimate pathological data (described below). All patients received taxane- and anthracyclinebased chemotherapies: 21 patients received AC-T chemotherapy and 16 patients underwent FEC-D chemotherapy. Twelve patients who were Her2/Neu positive received Trastuzumab during taxane chemotherapy. Patient characteristics are summarised in Table 1. Representative DOS parametric maps for responders and nonresponders, and the pretreatment MRI are shown in Figure 1.

Tumour haemoglobin and oxygenation - texture features demonstrate significant differences between response groups. Box-and-whisker plots for DOS-GLCM haemoglobin and $\mathrm{StO}_{2}$ features are presented in Figures 2 and 3, respectively. The deoxyhaemoglobin-homogeneity (Hb-hom) feature demonstrated a significant difference between responders and non-responders; $(P=0.030)$. The Hb-hom feature was greater in NR compared to $\mathrm{R}$ (mean value: $0.329 \pm 0.06$ (a.u.) ( \pm s.d.) vs $0.282 \pm 0.06$, respectively). However, other features such as the $\mathrm{Hb}$-con did not demonstrate a significant difference between groups $(P=0.066)$ (Figure 2). For the $\mathrm{HbO}_{2}$-GLCM features, the $\mathrm{HbO}_{2}$-cor was
Table 1. Patient and clinical characteristics

\begin{tabular}{|c|c|}
\hline Patient and tumour characteristics & $\begin{array}{c}n=37 \text { (All } \\
\text { subjects) }\end{array}$ \\
\hline \multicolumn{2}{|l|}{ Patients } \\
\hline Age (years) & 50 \\
\hline \multicolumn{2}{|l|}{ Pretreatment tumour size (MRI, cm) } \\
\hline $\begin{array}{l}\text { Responders } \\
\text { Non-responders }\end{array}$ & $\begin{array}{l}5.4 \\
7.0\end{array}$ \\
\hline \multicolumn{2}{|l|}{ Molecular and histological features } \\
\hline $\begin{array}{l}\text { ER }+ \\
\text { Triple negative/basal-like } \\
\text { HER2 }+ \\
\text { Invasive ductal carcinoma } \\
\text { Invasive lobular carcinoma }\end{array}$ & $\begin{array}{r}27 \\
7 \\
12 \\
36 \\
1\end{array}$ \\
\hline \multicolumn{2}{|l|}{ Treatment response classification } \\
\hline $\begin{array}{l}\text { Responders } \\
\text { Non-responders }\end{array}$ & $\begin{array}{l}27 \\
10\end{array}$ \\
\hline \multicolumn{2}{|c|}{ Chemotherapy and targeted therapies } \\
\hline $\begin{array}{l}\text { AC-T } \\
\text { FEC-D } \\
\text { Trastuzumab }\end{array}$ & $\begin{array}{l}21 \\
16 \\
12\end{array}$ \\
\hline \multicolumn{2}{|c|}{$\begin{array}{l}\text { Abbreviations: AC-T = adriamycin, cyclophosphamide, taxol; ER, oestrogen receptor } \\
\text { FEC-D = fluorouracil, epirubicin, cyclophosphamide, docetaxel; MRl, magnetic resonance } \\
\text { imaging. Patients included in the study were diagnosed with biopsy-confirmed locally } \\
\text { advanced breast cancer, and received a combination of anthracycline and taxane-basec } \\
\text { chemotherapies following standard institutional guidelines. }\end{array}$} \\
\hline
\end{tabular}

greater for responders $(R=0.205 \pm 0.06$ (a.u.) compared to $\mathrm{NR}=0.156 \pm 0.05$ (a.u.) (mean values), $P<0.024$ ). The HbT measurements in tumours demonstrated significant differences in homogeneity (HbT-hom) $(P=0.047)$. Other features were not significantly different such as the $\mathrm{HbO}_{2}$-con $(P=0.058)$ and $\mathrm{HbO}_{2}$-hom $(P=0.088)$.

There were also significant differences between response groups in tumour oxygenation texture features ( $\mathrm{St}$-con and $\mathrm{StO}_{2}$-con, $P<0.05)$. The St-con was significantly different between response groups $(P=0.044)$; while other features such as St-hom were close to being significantly different $(P=0.058)$. St-con measurements were greater in responders (mean value: $21.87 \pm 2.70$ (a.u.)) vs nonresponders (mean value $=20.43 \pm 1.41$ (a.u.) $)(P<0.05)$. Conversely the $\mathrm{StO}_{2}$-con parameter was greater in non-responders (mean value $=22.13 \pm 2.63$ (a.u.)) compared to responders (mean value $=19.87 \pm 3.02$ (a.u.) $)(P<0.05)$.

Diffuse optical spectroscopy texture features that were significantly different between response groups ( $\mathrm{N} v s \mathrm{NR}$ ) were analysed using the classifier models (Table 2A). In general, naive Bayes classification performed the best among the classifier models used in this study. For the HbT-hom, naive Bayes classification resulted in a $\% \mathrm{Sn}$ of $84 \%$, and $\% \mathrm{Sn}$ of $85 \%$ ( $\mathrm{AUC}=0.813$ ), in comparison to $k$-NN classification, which resulted in a classification of only $\% \mathrm{Sn}=74 \%, \% \mathrm{Sp}=47 \%$, and $\mathrm{AUC}$ of 0.552 (Table 2A). Analysis of all DOS texture features was also performed, independent of statistical significance between groups, using the three classifiers (logistic regression analysis, the naive Bayes model, or $k$-NN classifier). However, Table $2 \mathrm{~B}$ presents the best DOS texture features from all possible univariate features $(d=40)$ extracted from each classifier model. The corresponding ROC curves with AUCs are presented in Figure 4. Classification results from significant univariate texture features indicated an AUC range between 0.756 and 0.821 (Figure 4). A maximum AUC was observed for $\mathrm{HbO}_{2}$-hom $(\mathrm{AUC}=0.821)$ using a naive Bayes model. Cross validated \%Sn and \%Sp were $86.5 \%$, and $89.0 \%$, respectively, and corresponded to an accuracy of $87.8 \%$ (Table $2 \mathrm{~B}$ ). 

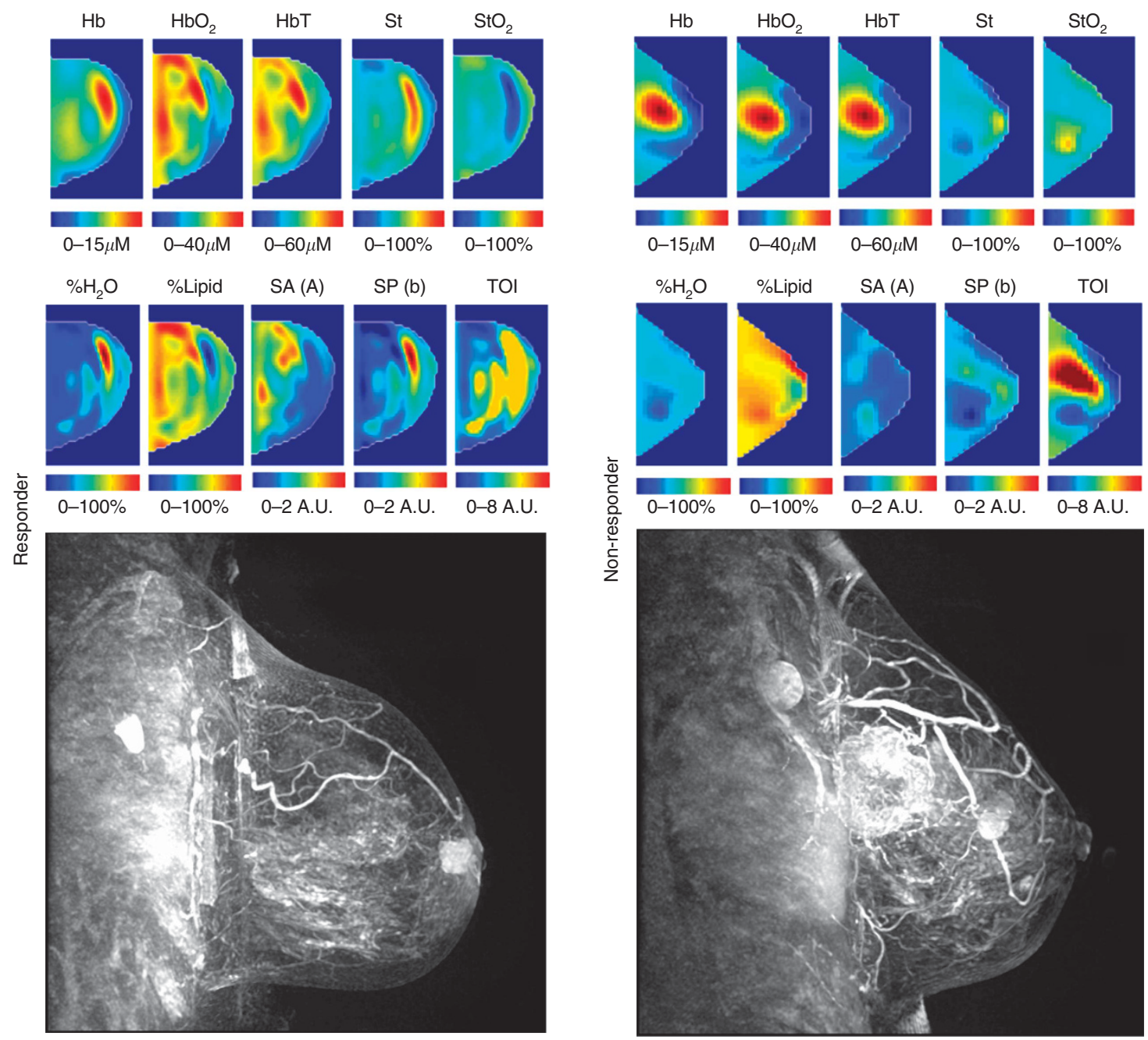

Figure 1. Representative responder vs non-responder. Representative DOS parametric maps for a responder (left column) and a non-responder (right column) are presented, and corresponding clinical contrast-enhanced magnetic resonance images of the breast. Baseline DOS images were acquired prior to starting NAC, using a tomographic diffuse optical spectroscopy device. Parametric maps were constructed volumetrically for analysis in order to calculate the GLCM texture features.

Other classifiers demonstrated a \% $\mathrm{Sn}$ range between 70.0 and $81.0 \%$, and a $\mathrm{Sp}$ of $70.0-73.0 \%$. This corresponded to an accuracy between 70 and $77 \%$ for logistic regression and $k$-NN classifiers, respectively.

Multivariate DOS-GLCM features. Table 2C presents classification results for pairwise DOS-GLCM feature combinations. The accuracy of optimal pairwise combinations was $77.8-79.5 \%$ for classifying response groups. Using a logistic regression analysis, the combination of $\mathrm{HbO}_{2}$-cor $+\mathrm{Hb}$-hom demonstrated a $\% \mathrm{Sn}$ of $80 \%$, and $\% \mathrm{Sp}$ of $78.0 \%$. This corresponded to an AUC of 0.815 , and an accuracy of $79.5 \%$. In comparison to the naive Bayes model, the optimal pairwise combination was observed using $\mathrm{Hb}$-con + $\mathrm{HbO}_{2}$-hom, which indicated a $\% \mathrm{Sn}$ and $\% \mathrm{Sp}$ of $78.0 \%$ and $81.0 \%$, respectively. The AUC for these combined parameters was 0.773 , and the accuracy was $79.5 \%$ (Figure 5; Table 2C). Finally, using the $k$-NN classifier, the best pairwise combination resulted from $\mathrm{Hb}$ cor and $\mathrm{HbO}_{2}$-con, which showed a $\% \mathrm{Sn}$ and $\% \mathrm{Sp}$ of $79.5 \%$ and $76.0 \%$, respectively. The corresponding AUC was 0.802 and the accuracy was $77.8 \%$ (Figure 5; Table 2C).

Multiple linear regression analysis and subgroup analysis. The results of the multiple linear regression demonstrated insignificant correlations between clinical features (age, ER/PR status, Her2 status, and tumour size) and DOS-GLCM features for this patient cohort. However, the $\mathrm{Hb}$-hom, $\mathrm{HbO}_{2}$-cor, and $\mathrm{StO}_{2}$-con features demonstrated significant correlations to MP grading, corresponding to a regression coefficient value $(r)$ of $-0.358,+0.375$, and -0.325 , respectively $(P<0.05)$. Results of the multiple regression analysis are presented in Table 3.

Subgroup analysis showed that the $\mathrm{HbO}_{2}$-hom feature was the best predictor in ER + patients using a naive Bayes classifier (Table 4). For patients with triple-negative tumours, the Hb-hom was the best predictor resulting in an AUC of 0.917 ( $\% \mathrm{Sn}=75.0 \%$, $66.7 \%)$ using a $k$-NN classifier. Patients separated according to chemotherapy groups also showed variances in optimal features; FEC-D-treated patients classified into responders and nonresponders with a $\%$ Sn of $100.0 \%$ and Sp of $92.3 \%$ using a logistic regression analysis for TOI-hom. Patients treated with AC-T-based chemotherapy demonstrated an AUC of 0.896 using the $\mathrm{HbO}_{2}$ hom feature with $k$-NN classification (Table 4).

\section{DISCUSSION AND CONCLUSION}

This study examined pretreatment DOS texture analysis and machine learning techniques to statistically measure textural heterogeneity in locally advanced breast tumours. These techniques were used to predict breast cancer response to anthracycline- and 

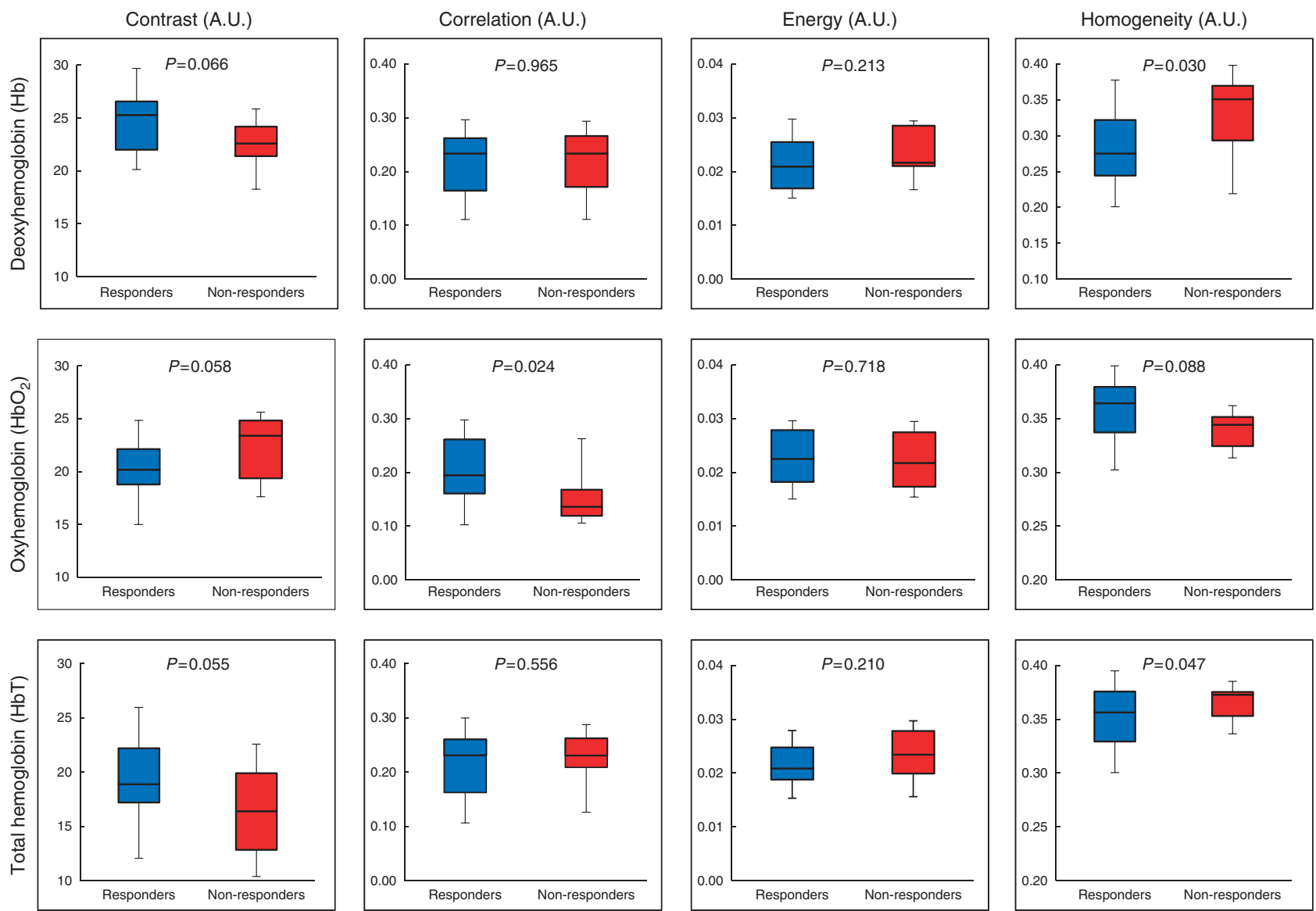

Figure 2. GLCM texture features for haemoglobin. Box-and-whisker plots showing significant differences in DOS textural markers for responders and non-responders. Haemoglobin-based features at baseline demonstrated a significant difference $(P<0.05)$ between response groups. An unpaired student $t$-test was used to test the significance for normally distributed data. $P$-values indicated.
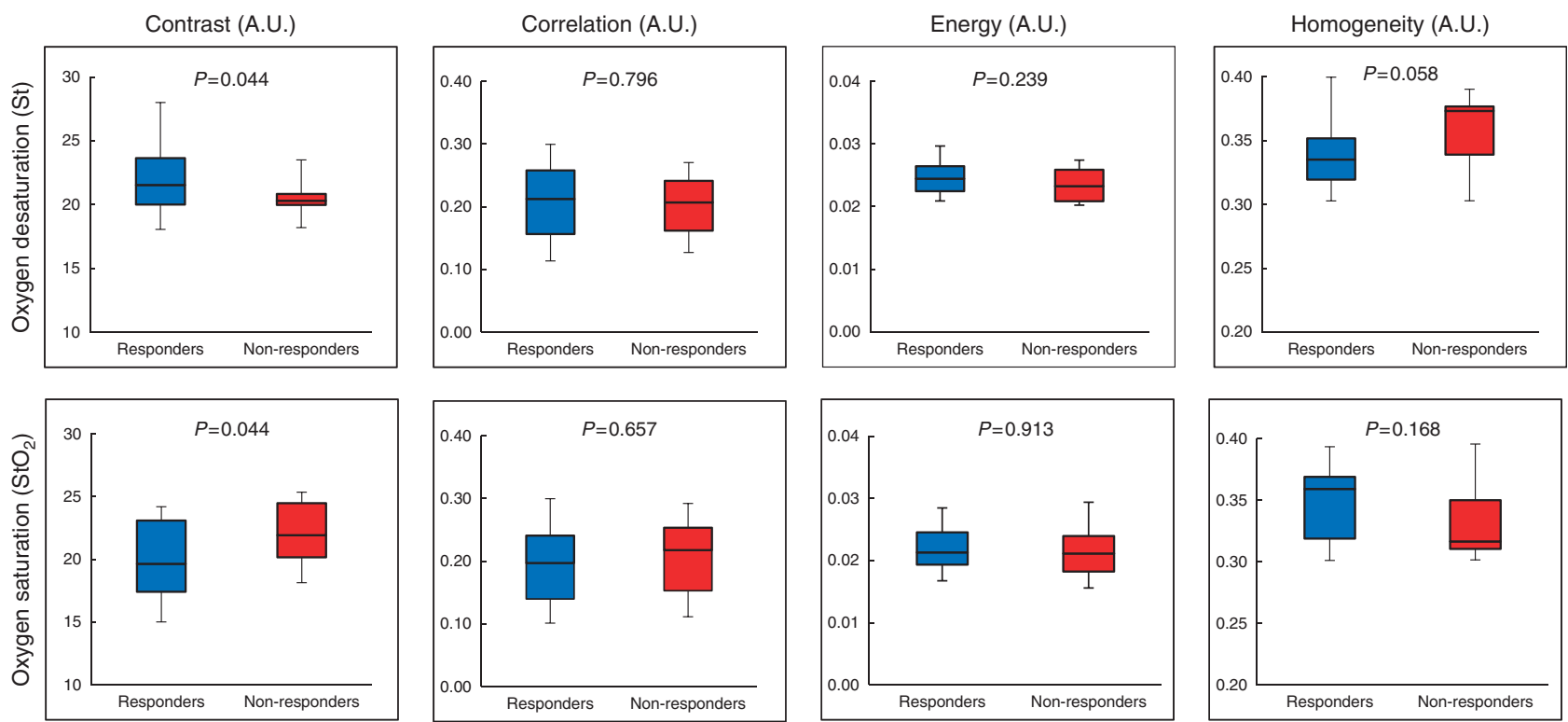

Figure 3. GLCM texture features for oxygen saturation. Box-and-whisker plots showing significant differences in DOS textural markers for responders and non-responders. Oxygen saturation parameters at baseline demonstrated a significant difference $(P<0.05)$ between response groups (unpaired student t-test, $P$-values indicated).

taxane-based NAC. The results demonstrate for the first time that textural heterogeneities in DOS measures of haemoglobin and oxygen content in breast tumours predict NAC response with high accuracy. Volumetric tumour analysis indicated that tumour- specific ROI-data can yield highly sensitive and specific univariate and multivariate textural markers using various classifier models.

Pretreatment DOS texture features $\left(\mathrm{Hb}, \mathrm{HbO}_{2}, \mathrm{HbT}\right.$, St, and $\mathrm{StO}_{2}$ ) were significantly different between responders and 
Table 2. Results of univariate (A, B) and multivariate analysis (C) using three classification models: logistic regression analysis, naive Bayes classifier, and $k-N N$

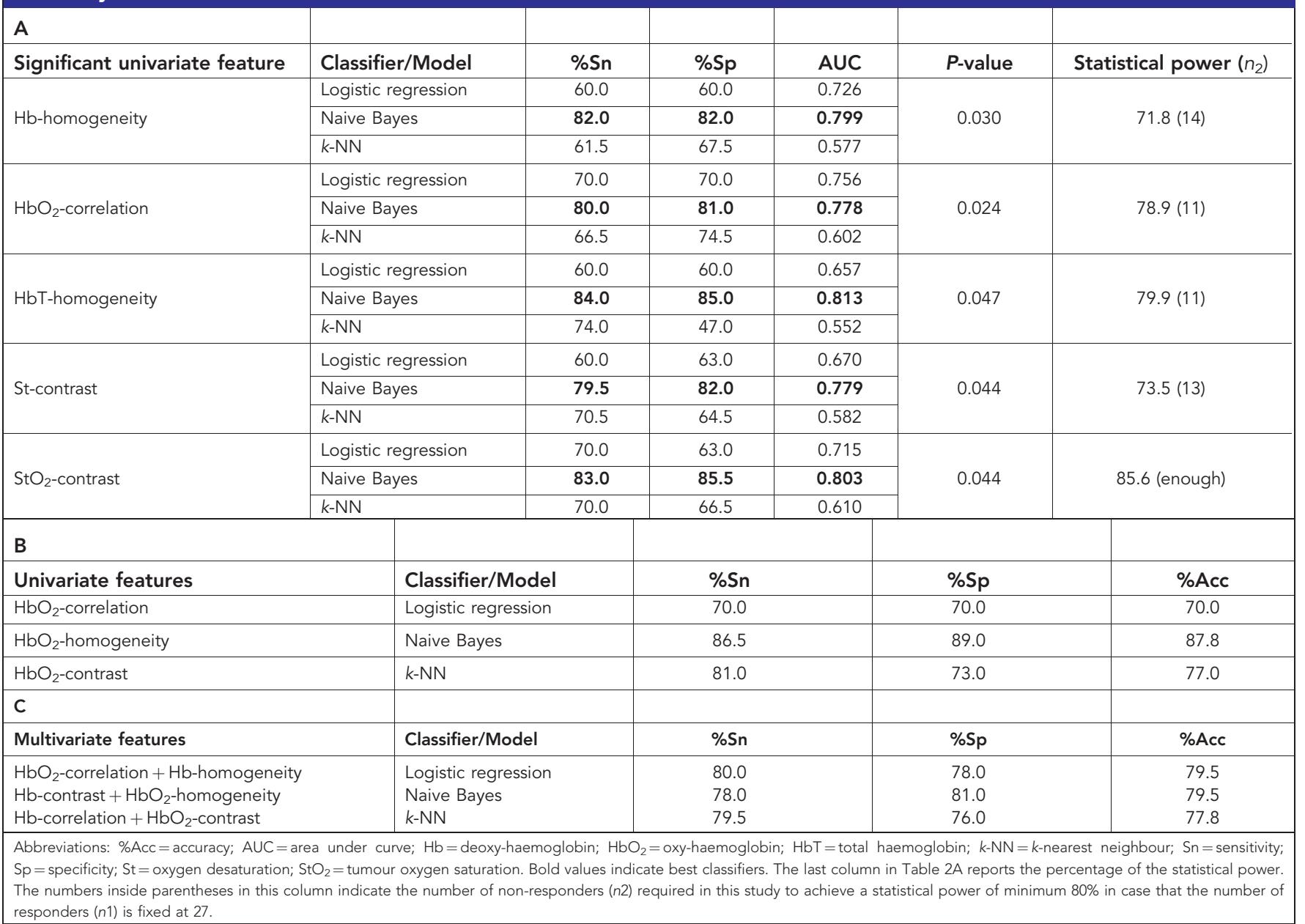

Logistic regression analysis

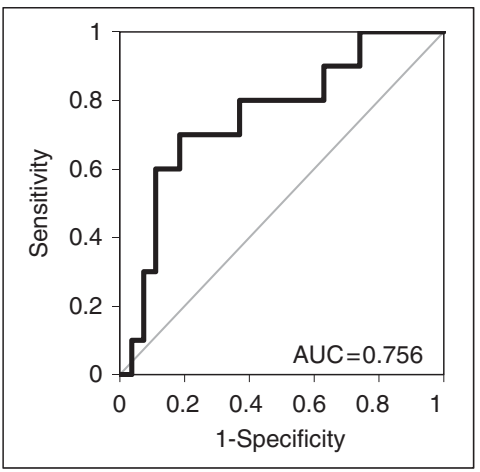

$\mathrm{HbO}_{2}$-Correlation
Naive Bayes model

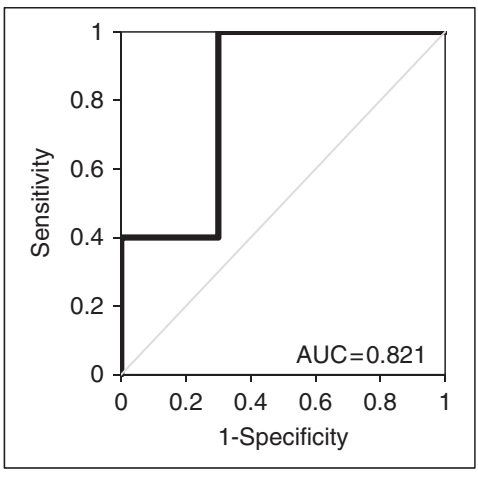

$\mathrm{HbO}_{2}$-Homogeneity

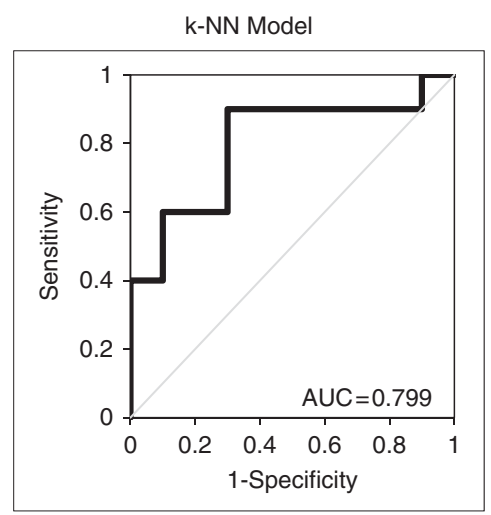

$\mathrm{HbO}_{2}$-Contrast

Figure 4. Receiver-operating characteristic (ROC) curves for univariate DOS texture features. ROC curves for the best performing single DOS texture parameter are presented.

non-responders. This relationship was also observed across patient subgroups separated by ER + , triple-negative, and chemotherapy treatments. Receiver-operating characteristic analysis of those features also indicated a good classification accuracy that represents heterogeneities in blood perfusion and $\mathrm{StO}_{2}$ in breast tumours. A previous study by Ueda et al (2012) demonstrated that pretreatment $\mathrm{StO}_{2}$ using the mean DOS values could predict treatment response with a \% Sn and $\%$ Sp of $75.0 \%$ and $73.3 \%$, respectively. The study here complements those results; demonstrating that texture-based analysis of the $\mathrm{StO}_{2}$-contrast may yield similar statistical differences between response groups $(P=0.044)$. Grey-level co-occurrence matrices analyses here, provided discriminant features by using volumetric tumour analysis, in addition to second-order statistical analyses that examined the pixel-by-pixel relationships of tumour heterogeneities within the parametric maps. Measures of spatial heterogeneity in tumour 
Logistic regression analysis

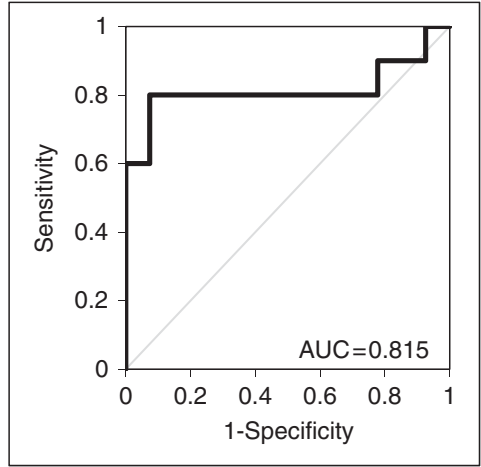

$\mathrm{HbO}_{2}$-Correlation $+\mathrm{Hb}$-Homogeneity

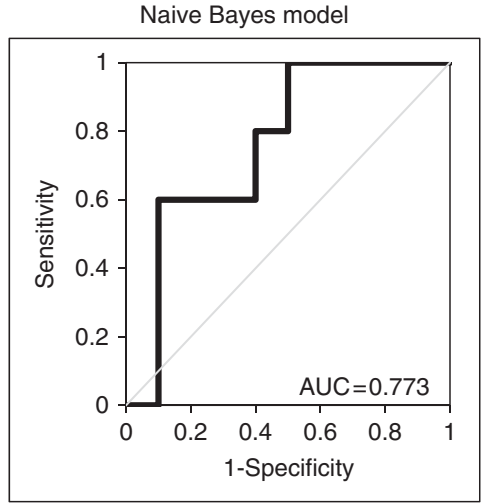

$\mathrm{Hb}$-Contrast $+\mathrm{HbO}_{2}-$ Homogeneity

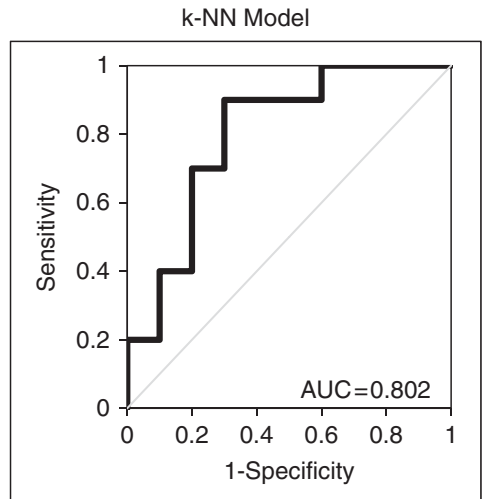

$\mathrm{Hb}$-Correlation $+\mathrm{HbO}_{2}$-Contrast

Figure 5. Receiver-operating characteristic (ROC) curves for multivariate DOS texture features. ROC curves for the best performing pairwise DOS texture parameters are presented.

Table 3. Regression coefficients ( $r$ ) of the multiple regression analysis for DOS-GLCM features and corresponding regression

\begin{tabular}{|c|c|c|c|c|}
\hline $\begin{array}{l}\text { DOS-GLCM } \\
\text { feature }\end{array}$ & Comparison & $r$ & $F$-value & $P$-value \\
\hline Hb-homogeneity & $\begin{array}{l}\text { Age } \\
\text { ER/PR status } \\
\text { Her2 status } \\
\text { Tumour size } \\
\text { Miller-Payne grade }\end{array}$ & $\begin{array}{l}-0.130 \\
-0.087 \\
-0.104 \\
+0.231 \\
-0.358\end{array}$ & $\begin{array}{l}0.599 \\
0.267 \\
0.382 \\
1.967 \\
5.137\end{array}$ & $\begin{array}{l}0.444 \\
0.608 \\
0.540 \\
0.170 \\
0.030\end{array}$ \\
\hline $\mathrm{HbO}_{2}$-correlation & $\begin{array}{l}\text { Age } \\
\text { ER/PR status } \\
\text { Her2 status } \\
\text { Tumour size } \\
\text { Miller-Payne grade }\end{array}$ & $\begin{array}{l}-0.116 \\
-0.003 \\
-0.109 \\
-0.295 \\
+0.375\end{array}$ & $\begin{array}{l}0.475 \\
0.000 \\
0.418 \\
3.335 \\
5.172\end{array}$ & $\begin{array}{l}0.495 \\
0.988 \\
0.522 \\
0.076 \\
0.022\end{array}$ \\
\hline HbT-homogeneity & $\begin{array}{l}\text { Age } \\
\text { ER/PR status } \\
\text { Her2 status } \\
\text { Tumour size } \\
\text { Miller-Payne grade }\end{array}$ & $\begin{array}{l}-0.142 \\
+0.007 \\
+0.206 \\
+0.085 \\
-0.233\end{array}$ & $\begin{array}{l}0.715 \\
0.002 \\
1.544 \\
0.257 \\
2.015\end{array}$ & $\begin{array}{l}0.403 \\
0.969 \\
0.222 \\
0.616 \\
0.165\end{array}$ \\
\hline St-contrast & $\begin{array}{l}\text { Age } \\
\text { ER/PR status } \\
\text { Her2 status } \\
\text { Tumour size } \\
\text { Miller-Payne grade }\end{array}$ & $\begin{array}{l}-0.231 \\
+0.056 \\
+0.095 \\
-0.164 \\
+0.177\end{array}$ & $\begin{array}{l}1.972 \\
0.111 \\
0.322 \\
0.971 \\
1.138\end{array}$ & $\begin{array}{l}0.169 \\
0.741 \\
0.574 \\
0.331 \\
0.293\end{array}$ \\
\hline $\mathrm{StO}_{2}$-contrast & $\begin{array}{l}\text { Age } \\
\text { ER/PR status } \\
\text { Her2 status } \\
\text { Tumour size } \\
\text { Miller-Payne grade }\end{array}$ & $\begin{array}{l}-0.083 \\
-0.074 \\
-0.213 \\
+0.279 \\
-0.325 \\
\end{array}$ & $\begin{array}{l}0.241 \\
0.190 \\
1.661 \\
2.966 \\
4.140\end{array}$ & $\begin{array}{l}0.626 \\
0.665 \\
0.206 \\
0.094 \\
0.050\end{array}$ \\
\hline
\end{tabular}

Abbreviations: $\mathrm{DOS}=$ diffuse optical spectroscopy; $\mathrm{ER}=$ oestrogen receptor; $\mathrm{GLCM}=$ greylevel co-occurrence matrices; $\mathrm{Hb}=$ deoxy-haemoglobin; $\mathrm{HbO}_{2}=$ oxy-haemoglobin; $\mathrm{HbT}=$ total haemoglobin; $\mathrm{PR}=$ progesterone receptor; $\mathrm{StO}_{2}=$ tumour oxygen saturation; $\mathrm{St}=$ oxygen desaturation. F-values are presented. Clinical features such as age, ER/PR status, Her2 status, and tumour size were not significantly correlated to DOS-GLCM features in this patient cohort. However, DOS-GLCM features such as the $\mathrm{Hb}$-hom, $\mathrm{HbO}_{2}$-cor, $\mathrm{StO}_{2}$-con were correlated to Miller-Payne pathologic response grade. Statistically significant values are in bold.

physiology as conducted here, could potentially provide good characterisation of biological traits that influence tumour response to treatment. Such features include tumour hypoxia (Hockel and Vaupel, 2001), and haematological characteristics such as blood flow and vascular density (Folkman, 2002). These features have been shown to influence tumour cell proliferation and metabolism, and therefore may also affect chemosensitivity (Folkman, 2002). The use of such measures better reflects tumour physiology, which is not homogeneous but rather spatially heterogeneous.
Table 4. A subgroup analysis was completed based on ER/ PR + and triple-negative tumours

\begin{tabular}{|c|c|c|c|c|c|}
\hline Subgroup & $\begin{array}{l}\text { Best } \\
\text { feature }\end{array}$ & Model & $\% \mathrm{Sn}$ & $\% S p$ & AUC \\
\hline ER/PR+ & $\begin{array}{l}\mathrm{Hb} \text {-con } \\
\mathrm{HbO}_{2} \text {-hom } \\
\mathrm{HbO}_{2} \text {-con }\end{array}$ & $\begin{array}{l}\text { Logistic } \\
\text { regression } \\
\text { Naive Bayes } \\
\text { k-NN }\end{array}$ & $\begin{array}{l}76.2 \\
93.3 \\
85.8 \\
\end{array}$ & $\begin{array}{l}66.7 \\
90.1 \\
82.5\end{array}$ & $\begin{array}{l}0.746 \\
0.883 \\
0.851\end{array}$ \\
\hline $\begin{array}{l}\text { Triple } \\
\text { negative }\end{array}$ & $\begin{array}{l}\text { Hb-hom } \\
\text { Hb-ene } \\
\text { Hb-hom }\end{array}$ & $\begin{array}{l}\text { Logistic } \\
\text { regression } \\
\text { Naive Bayes } \\
\text { k-NN }\end{array}$ & $\begin{array}{r}100.0 \\
100.0 \\
75.0\end{array}$ & $\begin{array}{l}33.3 \\
66.7 \\
66.7\end{array}$ & $\begin{array}{l}0.917 \\
0.667 \\
0.917\end{array}$ \\
\hline FEC-D & $\begin{array}{l}\text { TOl-hom } \\
\text { Hb-con } \\
\text { Hb-hom }\end{array}$ & $\begin{array}{l}\text { Logistic } \\
\text { regression } \\
\text { Naive Bayes } \\
\text { k-NN }\end{array}$ & $\begin{array}{r}100.0 \\
60.0 \\
80.0\end{array}$ & $\begin{array}{l}92.3 \\
81.7 \\
80.0\end{array}$ & $\begin{array}{l}0.949 \\
0.722 \\
0.806\end{array}$ \\
\hline AC-T & $\begin{array}{l}\mathrm{HbO}_{2} \text {-cor } \\
\mathrm{HbO}_{2} \text {-hom } \\
\mathrm{HbO}_{2} \text {-hom }\end{array}$ & $\begin{array}{l}\text { Logistic } \\
\text { regression } \\
\text { Naive Bayes } \\
\text { k-NN }\end{array}$ & $\begin{array}{l}100.0 \\
96.4 \\
83.6\end{array}$ & $\begin{array}{l}71.4 \\
90.7 \\
85.0\end{array}$ & $\begin{array}{l}0.837 \\
0.882 \\
0.896\end{array}$ \\
\hline
\end{tabular}

Abbreviations: $A C-T=$ adriamycin, cyclophosphamide, taxol; $A \cup C=$ area under curve; $E R=$ oestrogen receptor; FEC-D = fluorouracil, epirubicin, cyclophosphamide, docetaxel; $\mathrm{Hb}=$ deoxy-haemoglobin; $\mathrm{HbO}_{2}=$ oxy-haemoglobin; $k$-NN $=k$-nearest neighbour; $\mathrm{PR}=$ progesterone receptor; $\mathrm{Sn}=$ sensitivity; $\mathrm{Sp}=$ specificity; $\mathrm{TOI}=$ tissue optical index. Patients were also grouped according to chemotherapy type for analysis. Three classification models were used (logistic regression, naive Bayes, and k-NN) and the best predictive features are presented.

Additionally, multiparametric analysis resulted in sensitive and specific combined markers for response classification. Logistic regression analysis demonstrated $\sim 10 \%$ improvement in all performance measures by using pairwise features compared to the case of using only one single feature. However, the naive Bayes and $k$-NN did not show a significant improvement. This may be related to the small sample size used and peaking phenomena (Jain et al, 2000). Features into the pairwise models included: $\mathrm{HbO}_{2}$-cor, $\mathrm{HbO}_{2}-$ hom, $\mathrm{Hb}$-cor, $\mathrm{HbO}_{2}$-con, $\mathrm{Hb}$-hom, and $\mathrm{Hb}$-con. Individually, those non-texture DOS parameters were previously correlated to tumour vasculature (Intes, 2005). Additionally, the heterogenic tumour vasculature has been linked to mediating drug resistance; caused by structural scaffolds that inhibit effective drug delivery (Teicher et al, 1990; Galmarini et al, 2000; Tredan et al, 2007). These include poor vascular flow, increased interstitial fluid, and a tightly bound cellular matrix that may constrain drugs from reaching into the tumour stroma thereby affecting the efficacy of chemotherapies.

In comparison to other studies, texture analysis of MRI (Ahmed et al, 2013; Golden et al, 2013; Teruel et al, 2014), ultrasound 
spectroscopy (Sadeghi-Naini et al, 2014), and DOS (Sadeghi-Naini et al, 2015) images have been used to assess and monitor chemotherapy response in breast tumours during the course of treatment. Textural analysis of pretreatment MRI-based kinetic maps have indicated positive results for predicting chemotherapy response in 'triple-negative' breast tumours (Golden et al, 2013). Those results also strongly suggest that pretreatment tumour heterogeneity can influence drug resistance (Golden et al, 2013). Other similar studies have examined texture features of dynamic contrast-enhanced MRI images to predict NAC response (Ahmed et al, 2013; Teruel et al, 2014). Results have indicated significant differences in GLCM texture features between responders and non-responders at pretreatment (Ahmed et al, 2013) and have reported an increase in textural heterogeneity caused by necrotic tumour areas (Ahmed et al, 2013). Those studies demonstrated comparable frameworks to the present study. Specifically, that heterogeneous tumour features caused by pathophysiology, and initial biochemical composition might play an important role in chemoresistance.

In terms of novelty, the results indicate that selecting volumetric tumour-based ROIs may improve the method for DOS texture analysis to predict NAC response. Additionally, we compared the performance of several classification methods and found that using naive Bayes classifier demonstrated high accuracy in predicting chemotherapy treatment response. The preliminary work in this study highlights an important phase in the imaging biomarker roadmap' outlined by Cancer Research UK (CRUK) and the European Organisation for Research and Treatment of Cancer (EORTC) (O'Connor et al, 2017). Diffuse optical spectroscopybased biomarkers have surpassed the initial translational gap outlined within this roadmap; specifically, as a useful tool in medical research (O'Connor et al, 2017). Several works by Cerussi et al (2007), Tromberg et al (2005), and Roblyer et al (2011) have made significant contributions towards crossing the second translational gap; particularly, for DOS to be used as a clinical decision-making tool (Tromberg et al, 2005; Cerussi et al, 2007; Roblyer et al, 2011). In order for DOS-based imaging biomarkers to be considered clinically useful in personalised medicine, further research is required to build standard operating procedures for DOS imaging biomarkers for treatment response with validated cutoff points, removing bias, setting-up standard practices for image processing techniques and ensuring comparability to pathology (O'Connor et al, 2017). The work here builds on determining optimal techniques for where DOS could be used as a predictive or prognostic marker. Using DOS imaging biomarkers to guide cancer therapies can potentially reduce costs to the healthcare system by mitigating ineffective treatments. Therefore, DOS imaging used for routine cancer care would necessitate a costeffectiveness analysis to quantify the added value to the health-care system (O'Connor et al, 2017).

Limitations in this study include a limited sample size; although the patient cohort size has been improved compared to our previous study (Sadeghi-Naini et al, 2015). The statistical test of significance was performed with a relatively small sample size in each responding group $\left(n_{1}=27\right.$ and $n_{2}=10$ ) (Siegel and Castellan, 1988; de Winter, 2013). In order to evaluate the reliability of the performed tests, the statistical power (SP) was calculated using PASS $^{14}$ (NCSS, LLC. Kaysville, Utah, USA). The results obtained are reported in the rightmost column in Table $2 \mathrm{~A}$. As can be seen from these results, the SP for the statistically significant parameters varied between 71.8 and $85.6 \%$. This is one of the limitations of this study, as a threshold of $70 \%$ has to be considered for the SP instead of a commonly used threshold of $80 \%$. By fixing the number of responders $\left(n_{1}=27\right)$, we have also estimated the number of nonresponders $\left(n_{2}\right)$ required to achieve a minimum SP of $80 \%$, which are reported inside parentheses in the rightmost column in Table 2A. As can be seen from this analysis, at most four additional non-responders are needed to achieve an $80 \%$ SP. This change would permit stronger conclusions to be drawn from this study. We note that this study used binary response classifications ( $\mathrm{R} v s \mathrm{NR}$ ) and that the ratio of response groups in this cohort is biased towards the responders (complete pathologic and partial responders were grouped into one category). This was due to the chosen MP cutoff point.

Within the framework of the CRUK and EORTC imaging biomarker discovery roadmap, future work would require an increase in the number of patients to strengthen the statistical conclusions. This would subsequently allow classifying patients into multiple response categories (MP 1-5). Increasing the number of patients would also permit testing for repeatability, reproducibility, and would increase precision via multicentre trials (O'Connor et al, 2016). Baseline DOS imaging biomarkers could also be used to predict long-term survival data for patients. Taken together, these early results suggest that there is an opportunity for DOS-GLCM analysis to improve analysis and classification of tumour response prior to the start of NAC in breast patients.

In conclusion, this study investigated baseline DOS functional maps using GLCM texture analysis to classify patient response to NAC. In comparison to our previous study where we analysed DOS textures of the whole breast; here, we analysed the DOS texture features within the tumour region only (Sadeghi-Naini et al, 2015). The results indicated that such indices can differentiate between response groups prior to the start of treatment with high $\% \mathrm{Sn}$ and $\% \mathrm{Sp}$. Although further studies are required, this first report demonstrates promising potential for DOS-based textural parameters to evaluate baseline tumour vascular heterogeneity, and subsequently as markers for response to chemotherapy. The use of these markers may help guide treatments to personalise patientcare plans by potentially predicting chemoresponse. Ultimately if used to guide therapy, DOS-based texture analysis may help improve breast cancer therapeutics, and may potentially improve overall disease-free survival.

\section{ACKNOWLEDGEMENTS}

This project was funded by the Terry Fox Research Institute, Canada. We thank Professor Heidi Probst from Sheffield Hallam University (Sheffield, United Kingdom).

\section{CONFLICT OF INTEREST}

The authors declare no conflict of interest.

\section{REFERENCES}

Ahmed A, Gibbs P, Pickles M, Turnbull L (2013) Texture analysis in assessment and prediction of chemotherapy response in breast cancer. J Magn Reson Imaging 38: 89-101.

Cance WG, Carey LA, Calvo BF, Sartor C, Sawyer L, Moore DT, Rosenman J, Ollila DW, Graham 2nd M (2002) Long-term outcome of neoadjuvant therapy for locally advanced breast carcinoma: effective clinical downstaging allows breast preservation and predicts outstanding local control and survival. Ann Surg 236: 295-302discussion 302-3.

Castellano G, Bonilha L, Li LM, Cendes F (2004) Texture analysis of medical images. Clin Radiol 59: 1061-1069.

Cerussi A, Hsiang D, Shah N, Mehta R, Durkin A, Butler J, Tromberg BJ (2007) Predicting response to breast cancer neoadjuvant chemotherapy using diffuse optical spectroscopy. Proc Natl Acad Sci USA 104: 4014-4019.

Cerussi A, Shah N, Hsiang D, Durkin A, Butler J, Tromberg BJ (2006) In vivo absorption, scattering, and physiologic properties of 58 malignant breast 
tumors determined by broadband diffuse optical spectroscopy. J Biomed Opt 11: 044005.

Cerussi AE, Tanamai VW, Hsiang D, Butler J, Mehta RS, Tromberg BJ (2011) Diffuse optical spectroscopic imaging correlates with final pathological response in breast cancer neoadjuvant chemotherapy. Philos Trans A Math Phys Eng Sci 369: 4512-4530.

Chen W, Giger ML, Li H, Bick U, Newstead GM (2007) Volumetric texture analysis of breast lesions on contrast-enhanced magnetic resonance images. Magn Reson Med 58: 562-571.

Chicklore S, Goh V, Siddique M, Roy A, Marsden PK, COOK GJ (2013) Quantifying tumour heterogeneity in 18F-FDG PET/CT imaging by texture analysis. Eur J Nucl Med Mol Imaging 40: 133-140.

de Winter JCF (2013) Using the Student's $t$-test with extremely small sample sizes. Pract Assess Res Eval 18: 1-10.

Desantis CE, Lin CC, Mariotto AB, Siegel RL, Stein KD, Kramer JL, Alteri R, Robbins AS, Jemal A (2014) Cancer treatment and survivorship statistics, 2014. CA Cancer J Clin 64: 252-271.

Duda RO, Hart PE, Stork DG (2001) Pattern Classification. Wiley: New York.

Eisenhauer EA, Therasse P, Bogaerts J, Schwartz LH, Sargent D, Ford R, Dancey J, Arbuck S, Gwyther S, Mooney M, Rubinstein L, SHANKAR L, DODD L, KAPLAN R, Lacombe D, Verweij J (2009) New response evaluation criteria in solid tumours: revised RECIST guideline (version 1.1). Eur J Cancer 45: 228-247.

Evans A, Armstrong S, Whelehan P, Thomson K, Rauchhaus P, Purdie C, Jordan L, Jones L, Thompson A, Vinnicombe S (2013) Can shear-wave elastography predict response to neoadjuvant chemotherapy in women with invasive breast cancer? Br J Cancer 109: 2798-2802.

Folkman J (2002) Role of angiogenesis in tumor growth and metastasis. Semin Oncol 29: 15-18.

Galmarini FC, Galmarini CM, Sarchi MI, Abulafia J, Galmarini D (2000) Heterogeneous distribution of tumor blood supply affects the response to chemotherapy in patients with head and neck cancer. Microcirculation 7: 405-410.

Gibbs P, Turnbull LW (2003) Textural analysis of contrast-enhanced MR images of the breast. Magn Reson Med 50: 92-98.

Giordano SH (2003) Update on locally advanced breast cancer. Oncologist 8: 521-530.

Golden DI, Lipson JA, Telli ML, Ford JM, Rubin DL (2013) Dynamic contrast-enhanced MRI-based biomarkers of therapeutic response in triple-negative breast cancer. J Am Med Inform Assoc 20: 1059-1066.

Gupta R, Undrill PE (1995) The use of texture analysis to delineate suspicious masses in mammography. Phys Med Biol 40: 835-855.

Haralick RM, Shanmugam K, Dinstein I (1973) Textural features for image classification. IEEE Trans Syst Man Cybern 3: 610-621.

Hockel M, Vaupel P (2001) Tumor hypoxia: definitions and current clinical, biologic, and molecular aspects. J Natl Cancer Inst 93: 266-276.

Intes X (2005) Time-domain optical mammography SoftScan: initial results. Acad Radiol 12: 934-947.

Jain AK, Duin RPW, Mao J (2000) Statistical pattern recognition: a review. IEEE Trans Pattern Anal Mach Intell 22: 4-37.

Jakubowski DB, Cerussi AE, Bevilacqua F, Shah N, Hsiang D, Butler J, Tromberg BJ (2004) Monitoring neoadjuvant chemotherapy in breast cancer using quantitative diffuse optical spectroscopy: a case study. J Biomed Opt 9: 230-238.

Jiang S, Pogue BW, Kaufman PA, Gui J, Jermyn M, Frazee TE, Poplack SP, Diflorio-Alexander R, Wells WA, Paulsen KD (2014) Predicting breast tumor response to neoadjuvant chemotherapy with diffuse optical spectroscopic tomography prior to treatment. Clin Cancer Res 20: 6006-6015.

Lee MC, Newman LA (2007) Management of patients with locally advanced breast cancer. Surg Clin North Am 87: 379-398ix.

Lerski RA, Straughan K, Schad LR, Boyce D, Bluml S, Zuna I (1993) MR image texture analysis-an approach to tissue characterization. Magn Reson Imaging 11: 873-887.

Li H, Giger ML, Olopade OI, Margolis A, Lan L, Chinander MR (2005) Computerized texture analysis of mammographic parenchymal patterns of digitized mammograms. Acad Radiol 12: 863-873.

Mathew J, Asgeirsson KS, Cheung KL, Chan S, Dahda A, Robertson JF (2009) Neoadjuvant chemotherapy for locally advanced breast cancer: a review of the literature and future directions. Eur J Surg Oncol 35: 113-122.

Mourant JR, Canpolat M, Brocker C, Esponda-Ramos O, Johnson TM, Matanock A, Stetter K, Freyer JP (2000) Light scattering from cells: the contribution of the nucleus and the effects of proliferative status. J Biomed Opt 5: 131-137.
National Institute For Health And Clinical Excellence (NICE) (2009) Early and Locally Advanced Breast Cancer: Diagnosis and Treatment. NICE: Cardiff, UK.

O'Connor JP, Aboagye EO, Adams JE, Aerts HJ, Barrington SF, Beer AJ, Boellaard R, Bohndiek SE, Brady M, Brown G, Buckley DL, Chenevert TL, Clarke LP, Collette S, Cook GJ, Desouza NM, Dickson JC, Dive C, Evelhoch JL, Faivre-Finn C, Gallagher FA, Gilbert FJ, Gillies RJ, Goh V, Griffiths JR, Groves AM, Halligan S, Harris AL, Hawkes DJ, Hoekstra OS, Huang EP, Hutton BF, Jackson EF, Jayson GC, Jones A, Koh DM, Lacombe D, Lambin P, Lassau N, Leach MO, Lee TY, Leen EL, Lewis JS, Liu Y, Lythgoe MF, Manoharan P, Maxwell RJ, Miles KA, Morgan B, Morris S, Ng T, Padhani AR, Parker GJ, Partridge M, Pathak AP, Peet AC, Punwani S, Reynolds AR, Robinson SP, Shankar LK, Sharma RA, Soloviev D, Stroobants S, Sullivan DC, Taylor SA, Tofts PS, Tozer GM, Van Herk M, Walker-Samuel S, Wason J, Williams KJ, Workman P, Yankeelov TE, Brindle KM, Mcshane LM, Jackson A, Waterton JC (2017) Imaging biomarker roadmap for cancer studies. Nat Rev Clin Oncol 14: 169-186.

Ogston KN, Miller ID, Payne S, Hutcheon AW, Sarkar TK, Smith I, Schofield A, Heys SD (2003) A new histological grading system to assess response of breast cancers to primary chemotherapy: prognostic significance and survival. Breast 12: 320-327.

Provenzano E, Bossuyt V, Viale G, Cameron D, Badve S, Denkert C, Macgrogan G, Penault-Llorca F, Boughey J, Curigliano G, Dixon JM, Esserman L, Fastner G, Kuehn T, Peintinger F, von Minckwitz G, White J, Yang W, Symmans WF, Residual Disease Characterization Working Group Of The Breast International Group-North American Breast Cancer Group, C (2015) Standardization of pathologic evaluation and reporting of postneoadjuvant specimens in clinical trials of breast cancer: recommendations from an International Working Group. Mod Pathol 28: 1185-1201.

Roblyer D, Ueda S, Cerussi A, Tanamai W, Durkin A, Mehta R, Hsiang D, Butler JA, Mclaren C, Chen WP, Tromberg B (2011) Optical imaging of breast cancer oxyhemoglobin flare correlates with neoadjuvant chemotherapy response one day after starting treatment. Proc Natl Acad Sci USA 108: 14626-14631.

Sadeghi-Naini A, Sannachi L, Pritchard K, Trudeau M, Gandhi S, Wright FC, Zubovits J, Yaffe MJ, Kolios MC, Czarnota GJ (2014) Early prediction of therapy responses and outcomes in breast cancer patients using quantitative ultrasound spectral texture. Oncotarget $\mathbf{5}$ : 3497-3511.

Sadeghi-Naini A, Vorauer E, Chin L, Falou O, Tran WT, Wright FC, Gandhi S, Yaffe MJ, Czarnota GJ (2015) Early detection of chemotherapyrefractory patients by monitoring textural alterations in diffuse optical spectroscopic images. Med Phys 42: 6130-6146.

Schaafsma BE, Van De Giessen M, Charehbili A, Smit VT, Kroep JR, Lelieveldt BP, Liefers GJ, Chan A, Lowik CW, Dijkstra J, Van De Velde CJ, Wasser MN, Vahrmeijer AL (2015) Optical mammography using diffuse optical spectroscopy for monitoring tumor response to neoadjuvant chemotherapy in women with locally advanced breast cancer. Clin Cancer Res 21: $577-584$.

Siegel S, Castellan NJ (1988) Nonparametric Statistics for the Behavioral Sciences. McGraw-Hill: New York.

Teicher BA, Herman TS, Holden SA, Wang YY, Pfeffer MR, Crawford JW, Frei 3rd E (1990) Tumor resistance to alkylating agents conferred by mechanisms operative only in vivo. Science 247: 1457-1461.

Teruel JR, Heldahl MG, Goa PE, Pickles M, Lundgren S, Bathen TF, Gibbs P (2014) Dynamic contrast-enhanced MRI texture analysis for pretreatment prediction of clinical and pathological response to neoadjuvant chemotherapy in patients with locally advanced breast cancer. $N M R$ Biomed 27: 887-896.

Tredan O, Galmarini CM, Patel K, Tannock IF (2007) Drug resistance and the solid tumor microenvironment. J Natl Cancer Inst 99: 1441-1454.

Tromberg BJ, Cerussi A, Shah N, Compton M, Durkin A, Hsiang D, Butler J, Mehta R (2005) Imaging in breast cancer: diffuse optics in breast cancer: detecting tumors in pre-menopausal women and monitoring neoadjuvant chemotherapy. Breast Cancer Res 7: 279-285.

Ueda S, Roblyer D, Cerussi A, Durkin A, Leproux A, Santoro Y, Xu S, O'Sullivan TD, Hsiang D, Mehta R, Butler J, Tromberg BJ (2012) Baseline tumor oxygen saturation correlates with a pathologic complete response in breast cancer patients undergoing neoadjuvant chemotherapy. Cancer Res 72: 4318-4328. 
von Minckwitz G, Untch M, Blohmer JU, Costa SD, Eidtmann H, Fasching PA, Gerber B, Eiermann W, Hilfrich J, Huober J, Jackisch C, Kaufmann M, Konecny GE, Denkert C, Nekljudova V, Mehta K, Loibl S (2012) Definition and impact of pathologic complete response on prognosis after neoadjuvant chemotherapy in various intrinsic breast cancer subtypes. J Clin Oncol 30: 1796-1804.

Whitman GJ, Strom EA (2009) Workup and staging of locally advanced breast cancer. Semin Radiat Oncol 19: 211-221.

Xu RX, Povoski SP (2007) Diffuse optical imaging and spectroscopy for cancer. Expert Rev Med Devices 4: 83-95.
Yang X, Tridandapani S, Beitler JJ, Yu DS, Yoshida EJ, Curran WJ, Liu T (2012) Ultrasound GLCM texture analysis of radiation-induced parotidgland injury in head-and-neck cancer radiotherapy: an in vivo study of late toxicity. Med Phys 39: 5732-5739.

This work is published under the standard license to publish agreement. After 12 months the work will become freely available and the license terms will switch to a Creative Commons AttributionNonCommercial-Share Alike 4.0 Unported License.

Supplementary Information accompanies this paper on British Journal of Cancer website (http://www.nature.com/bjc) 